\title{
When Cancer Patient Needs to Cry
}

\section{Luisa Pedrero Gil*}

Psycho-oncologist, Malaga, Andalusia, Spain

*Corresponding Author: Luisa Pedrero Gil, Psycho-oncologist, Malaga, Andalusia, Spain.

At birth, just as we come with a pair of legs, eyes, lungs, arms, etc. Also comes with us a "pack" of emotions. There are sadness, joy, anger, surprise, disgust and fear. These are our basic emotions, and all the others come from them.

As we get older, they teach us to move our legs correctly, to be able to walk, to move our arms and hands to be able to catch the drinks, and gradually we take over our body, the coordination improves.

But what about the pack of emotions? Nobody teaches us this.

Unfortunately, we have been dragging cultural patterns where what is transmitted is to avoid and/or ignore what we feel. From a young age we hear things like, "Don't get angry" "Don't cry" "You don't have to wear like that."

That's how we grow and that's how we're doing.

Canceling, hiding and avoiding expressing our emotions. With the feeling that there is something wrong with them, and that if we let them out, it is because we are weak or not very intelligent.

Nature is not wrong, this pack of emotions has its raison d'em ratio. Each and every one of them helps us cope with situations.

For example, sadness, which we normally express with crying, is the only emotion that leads us to deep reflex, to look in. And, it is only after reflection that we are able to generate change, an improvement in oneself, or at least allow us to develop a strategy to get out of the situation that is drowning us. If we are denied using this capability, what kind of decisions will we make, but allow us to look in?

Sadness is necessary for life, it is a time when the body asks us to stop, to be alone, to reflect, to think. And it's okay to let her be here for a time. Now, we must not let it settle in our lives either.
Received: February 27, 2020

Published: April 27, 2020

(C) All rights are reserved by Luisa Pedrero Gil.
The story of the Master and the disciple makes it very clear:

The Master asked the disciple:

Why don't you come up to the river' edge?

"Because I'm afraid of falling into the water and drowning," he replied No one drowns from falling into the water. What drowns you is there remains within, said the Master

You're not going to drown out from letting in the sadness, it will drown you and lead you to depression if you let it settle into your life.

And the million-dollar question: How do we prevent sadness from settling into our lives?

Well, very easy, learning the curve of sadness. And here I explain it:

Sadness always soars with a thought, and this is the beginning of the upward curve. This thought will generate chemical changes in our body (heartbeat increases, eyes moisten, knot in garganta...) and so we're slowly climbing the curve. We know the crying is coming.

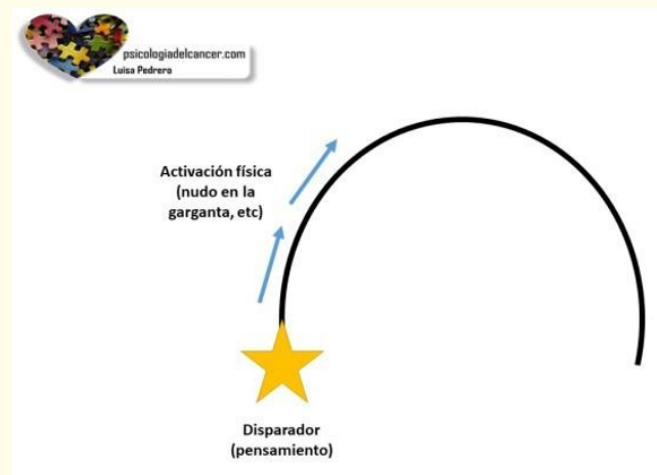

Figure 1 
It's right now, when a lot of people stop this "activation" because they know perfectly well that they're going to cry and don't want to. Either for fear of getting carried away, or because you have the belief that crying will weaken you, or because you're still in a place surrounded by people and you don't feel like it.

The problem is when whenever you start the "activation" of you, you stop it.

Why is it a problem? Because you're interrupting a natural process of relaxation.

You stop one, you stop another, and another. We're afraid to get carried away. We're afraid to cry.

In the end you become a time bomb, which sooner or later, when and where you least expect it, you will explode and lose the control that you long to hold.

But let's imagine that you don't stop the "activation", which you get carried away.

When we reach the highest part of the curve, it's that moment of heavy crying, that which hurts the chest, that the tears come out and come out non-stop, and that often, it costs to breathe. Our thoughts turn around, are painful thoughts, they come strongly, and we feel we will no longer be able to.

But I have good news for you, this time it doesn't last more than 10 minutes. There are studies that indicate that physiologically we stay on this activation of 5 to $10 \mathrm{~min}$, no more.

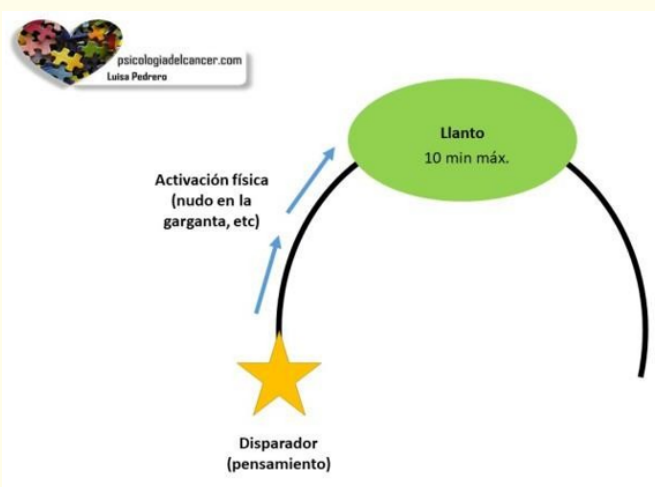

Figure 2
Then little by little we started to lower the curve. Our body naturally closes tears, the heartbeat normalizes, our muscles feel more relaxed, the breathing is calmed.

Sadness is still there, but not the tension in the body. We don't cry anymore, the tears just don't come out anymore, we feel calmer, we have more peace. In fact, many people fall asleep soundly after a moment of crying. And this is because crying relaxes us, removes the tension accumulated in the body, removes the annoying knot in the throat, in other words it suits us!

Our body is very wise. You know exactly what you're doing, the problem is that we're not done with understanding you.

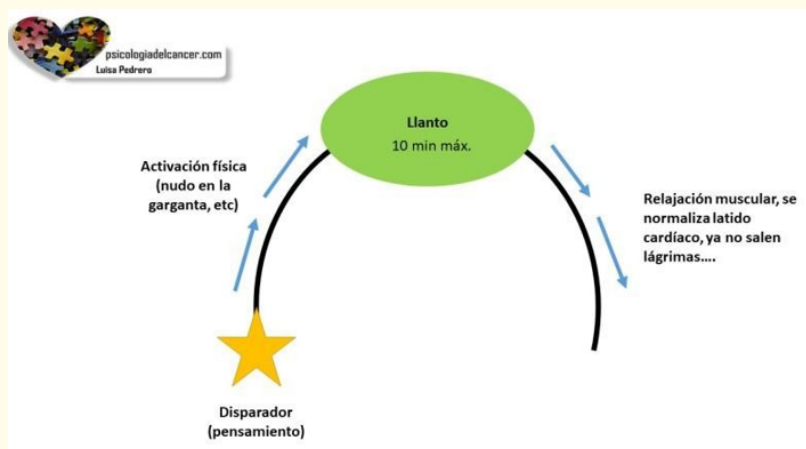

Figure 3

Now, since we have descended on the curve of sadness/crying and our body has returned to normal, this is where we should pay attention.

It is right now that makes the difference between those who have used crying as a method of relaxation or who uses it as an anchor without realizing it. Let's call this moment: Zero Moment.

This is where you have to be aware of what your body is marking you, that is, the tension is gone, and that's when you have to get up and follow. Wash your face and go for a walk, start making a cake, call a friend, whatever, but get out of there, break with the curve and finish the process correctly.

The problem is that many people stay there and allow another thought of sadness to appear and activate the curve again, and again and again. And this instead of relaxing the body, stresses it, and anchors it in sadness, or as the story of the master says, leaves you in the water, and causes us to drown. 


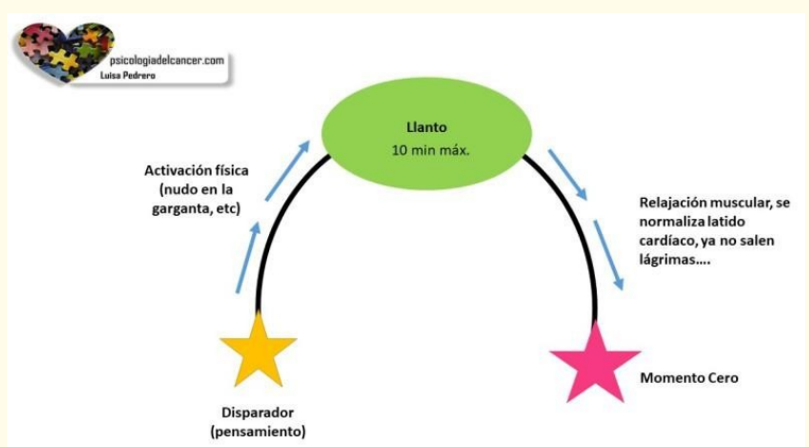

Figure 4

Everyone has the ability to decide what they're going to do at zero time, or stay and keep ruminating and turning their heads, or get up, and keep going. To recite that you are always in control, and that we cannot help but feel sad, what if we can avoid is to be anchored in sadness.

Emotions are our allies; you only have to learn and understand what your true purpose is.

Be patient and listen to your body, he is setting up the pace many times.

Luisa Pedrero Gil Psicooncoologist España, February 2020.

\section{Assets from publication with us}

- Prompt Acknowledgement after receiving the article

- Thorough Double blinded peer review

- Rapid Publication

- Issue of Publication Certificate

- High visibility of your Published work

Website: https://www.actascientific.com/

Submit Article: https://www.actascientific.com/submission.php

Email us: editor@actascientific.com

Contact us: +919182824667 